\title{
MAXIMUM ECONOMIC YIELD SUMBERDAYA PERIKANAN KERAPU DI PERAIRAN KEPULAUAN SERIBU, DKI JAKARTA
}

\author{
Yesi Dewita Sari', Tridoyo Kusumastanto², Luky Adrianto
}

Penelitian ini bertujuan mengetahui jumlah hasil tangkapan ikan kerapu yang optimal dilihat dari segi ekonomi dengan tetap didasarkan pada keberlanjutan pemanfaatan sumberdaya. Penelitian dilakukan di wilayah Kepulauan Seribu menggunakan data primer dan data sekunder. Data primer diperoleh melalui wawancara dengan nelayan yang melakukan penangkapan ikan kerapu dengan menggunakan alat tangkap pancing dan bubu. Data sekunder diperoleh dari kantor kecamatan, bupati dan Dinas Peternakan Perikanan dan Kelautan DKI Jakarta. Data sekunder dianalisis selama 14 tahun mulai tahun 1990 sampai tahun 2004. Analisis bioekonomi dengan model surplus produksi perikanan yang dikemukakan oleh Clark, Yoshimoto dan Pooley digunakan dalam penelitian ini. Optimal pemanfaatan secara ekonomi pada pengelolaan sumberdaya perikanan kerapu di perairan Kepulauan Seribu DKI Jakarta adalah pada tingkat upaya penangkapan 82 unit setara dengan bubu, jumlah hasil tangkapan 29,94 ton per tahun dan manfaat ekonomi 747 juta rupiah per tahun. Tingkat pemanfaatan yang dilakukan oleh nelayan baik dilihat dari jumlah alat tangkap yang digunakan maupun hasil yang didaratkan telah menunjukkan kondisi tangkap lebih sehingga diperlukan kebijakan pemerintah untuk membatasi tingkat pemanfaatan sumberdaya ikan kerapu tersebut.

\section{Kata kunci: Maximum Economic Yield, Kepulauan Seribu, Kerapu}

\section{Abstract: Maximum Economic Yield of Grouper Resource in the Kepulauan Seribu, DKI Jakarta by Yesi Dewita Sari, Tridoyo Kusumastanto and Luky Adrianto}

This research aimed to calculate groupers optimum exploitation in economic term based on resource sustainability. The research conducted at the Kepulauan Seribu using primary and secondary data. Primary data were collected from hookline and trap fishers using interview technique, while secondary data were collected from sub district, district and marine, fisheries and animal husbandry services of DKI Jakarta Province. Data series of 1990 to 2004 were also analyzed. Bioeconomic analysis with surplus production model developed by Clark, Yoshimoto and Pooley was used in this study. Optimum economic exploitation of groupers fishery management were 82 unit fishing effort, 29,94 ton per year productions and Rp 747.000.000 economic rent per year. Exploitation rate carried out by fishers at Kepulauan Seribu had indicated over exploitation so that government policy to limit the fishing effort should be imposed.

Keyword: Maximum Economic Yield, Kepulauan Seribu, Grouper

\section{PENDAHULUAN}

Sumberdaya perikanan pada dasarnya bersifat terbatas walaupun sumberdaya tersebut dapat pulih kembali. Pada wilayah yang belum dimanfaatkan, stok ikan akan tumbuh sampai mencapai tingkat daya dukung lingkungan (carrying capacity).
Sumberdaya perikanan karang merupakan salah satu jenis sumberdya perikanan yang telah dimanfaatkan dalam jumlah besar. Besarnya tingkat pemanfaatan sumberdaya ikan karang terutama ikan kerapu disebabkan karena adanya permintaan pasar luar negeri yaitu ikan karang hidup konsumsi atau lebih

\footnotetext{
${ }^{1}$ Peneliti pada Balai Besar Riset Sosial Ekonomi Kelautan dan Perikanan, BRKP-DKP

${ }^{2}$ Kepala Pusat Kajian Sumberdaya Pesisir dan Lautan PKSPL-IPB dan Ketua Program Studi Ekonomi Sumberdaya Kelautan Tropika

${ }^{3}$ Dosen pada Program Studi Ekonomi Sumberdaya Kelautan Tropika ESK-SPS-IPB
} 
dikenal Live Reef Fish for Food (LRFF). Permintaan ikan karang hidup konsumsi ini sebagian besar berasal dari Hongkong. Ikan karang hidup konsumsi ini biasanya dikonsumsi pada acara-acara tertentu seperti pertemuan keluarga, syukuran dan juga peringatan hari-hari besar keagamaan.

Kepulauan Seribu merupakan suatu wilayah khas yang terletak di wilayah Teluk Jakarta dengan berbagai potensi perikanan yang cukup beragam antara lain ikan konsumsi, ikan hias, terumbu karang (coral reef), rumput laut serta mangrove. Ikan konsumsi yang banyak atau yang paling disukai untuk ditangkap oleh nelayan di perairan Kepulauan Seribu adalah ikan karang antara lain jenis ikan kerapu (famili Serranidae).

Dengan luas areal daratan sekitar 834,65 ha dan luas perairan laut sekitar $7.000 \mathrm{~km}^{2}$ (Bappeda DKI Jakarta, 2000) serta jumlah pulau sebanyak 105 buah Kabupaten Administrasi Kepulauan Seribu memiliki potensi sumberdaya perikanan sebagai berikut: (1) Jumlah nelayan sekitar 11.773 orang, terdiri dari 9.008 orang nelayan penetap dan 2.765 orang nelayan pendatang (2) Total sarana alat tangkap 1.206 berupa kapal motor, 94 motor tempel dan 101 perahu (Dinas Peternakan, Perikanan dan Kelautan Provinsi DKI Jakarta). Berdasarkan potensi tersebut belum diketahui berapa besar jumlah hasil tangkapan yang optimal dapat didaratkan dari perairan Kepulauan Seribu serta jumlah upaya penangkapan optimal yang diperbolehkan beroperasi. Sedangkan beberapa penelitian sebelumnya menunjukkan bahwa jumlah hasil tangkapan terutama ikan-ikan karang telah menunjukkan angka yang semakin menurun. Oleh karena itu penelitian ini dilakukan untuk mengetahui seberapa besar tingkat pemanfaatan sumberdaya ikan kerapu di perairan Kepulauan Seribu yang telah dilakukan dan berapa tingkat pemanfaatan optimal yang seharusnya dilakukan dilihat dari aspek ekonomi.

\section{METODOLOGI}

\section{Metode Penelitian}

Metode yang digunakan dalam penelitian ini adalah studi kasus. Menurut Nazir (1988), hasil dari penelitian kasus merupakan suatu generalisasi dari pola-pola kasus yang tipikal dari individu, kelompok, lembaga dan sebagainya. Studi kasus lebih mengkaji variabel yang cukup banyak pada jumlah unit yang kecil dan mempunyai keunggulan sebagai suatu studi untuk mendukung studistudi yang besar di kemudian hari. Studi kasus dapat memberikan hipotesa-hipotesa untuk penelitian lanjutan. Dari segi edukatif, studi kasus dapat digunakan sebagai contoh ilustrasi baik dalam perumusan masalah, penggunaan statistik dalam menganalisa data serta cara-cara perumusan generalisasi dan kesimpulan.

\section{Lokasi dan Waktu Penelitian}

Penelitian ini dilakukan di perairan yang termasuk dalam wilayah administrasi Kabupaten Kepulauan Seribu. Kabupaten Kepulauan Seribu merupakan kabupaten pemekaran dari Kota Jakarta Utara, Provinsi DKI Jakarta. Kepulauan Seribu terletak di sebelah utara Kota Jakarta yang terdiri dari 105 pulau dengan 11 pulau berpenghuni.

Penelitian berlangsung selama 4 bulan mulai bulan Agustus tahun 2004 sampai dengan bulan Desember tahun 2004 meliputi tahap persiapan, pengumpulan data baik data primer maupun data sekunder. Tahapan setelah pengumpulan adalah pengolahan data, penyusunan model dan verifikasi model.

\section{Model Pendekatan yang Digunakan}

Model yang digunakan dalam penelitian ini adalah model surplus produksi. Salah model surplus produksi yang sesuai dengan penelitian ini adalah model pertumbuhan logistik yang dikemukakan oleh Schaefer 1954. Bentuk umum fungsi pertumbuhan logistik ini adalah:

$$
\frac{\partial X}{\partial t}=r X\left(1-\frac{X}{K}\right)-h
$$


dimana:

$$
\begin{aligned}
& \mathrm{X}=\text { stokikan/fish stock } \\
& \mathrm{r}=\mathrm{I} \mathrm{aju} \mathrm{pertumbuh} \mathrm{a} \mathrm{n} \\
& \text { intrinsik/intrinsic growth rate } \\
& \mathrm{K} \text { = daya dukung lingkungan/ } \\
& \text { carrying capacity } \\
& \mathrm{h}=\text { hasil tangkapan/ harvest }
\end{aligned}
$$

Bentuk fungsi logistik adalah bentuk simetris di mana ada titik puncak kuadratik. Jika stok sumberdaya perikanan mulai dieksploitasi oleh nelayan, maka laju eksploitasi sumberdaya perikanan dalam satuan waktu tertentu diasumsikan merupakan fungsi dari input (effort) yang digunakan dalam menangkap ikan dan stok sumberdaya yang tersedia. Dalam fungsi hubungan itu dapat dituliskan (Fauzi, 2004) sebagai berikut :

$$
h=H(E, X)
$$

Selanjutnya diasumsikan bahwa laju penangkapan linier terhadap biomass dan effort yaitu :

$$
h=q E X
$$

dimana :

$\mathrm{q}=$ Koefisien kemampuan penangkapan /catchability coefisien

$\mathrm{E}=$ Upaya penangkapan/effort

Asumsi dalam kondisi keseimbangan $\left(\frac{\partial X}{\partial t}=0\right)$, maka X dapat dipecahkan sebagai

variabel dari E. Dengan mensubstitusikan nilai $\mathrm{X}$ tersebut maka fungsi penangkapan dapat dituliskan sebagai berikut:

$$
h=q K E-\left(\frac{q^{2} K}{r}\right) E^{2}
$$

Rente ekonomi dari pemanfaatan sumberdaya ikan kerapu di perairan Kepulauan Seribu dapat dituliskan menjadi:

$$
\pi=T R-T C \text { atau dapat dituliskan }
$$

$\pi=p h-c E$ dengan mensubtitusikan $\mathrm{h}$, menjadi:

$$
\pi=p \cdot\left(q K E\left(1-\frac{q}{r} E\right)\right)-c E
$$

Pada kondisi maximum economic yield, maka MR=TC dapat dituliskan sebagai berikut:

$$
p q K-2 p E\left(\frac{q^{2} K}{r}\right)=c
$$

Dengan memecahkan persamaan tersebut diatas dapat diketahui jumlah $\mathrm{E}$ (upaya penangkapan optimal pada kondisi MEY yaitu:

$$
E^{*}=\frac{r}{2 q}\left(1-\frac{c}{p q K}\right)
$$

\section{Jenis, Sumber dan Teknik Pengumpulan Data}

Data yang dikumpulkan adalah data primer dan data sekunder. Data primer adalah data yang langsung diperoleh dari pengamatan atau pengukuran langsung dari objek penelitian. Dalam penelitian ini, pengumpulan data primer dilakukan dengan cara wawancara langsung dengan para nelayan, para pembudidaya ikan. Dalam penelitian ini, pengumpulan data primer dilakukan dengan cara wawancara langsung dengannelayan, pembudidaya ikan, para pejabat pemerintah pengelola sumberdaya perikanan dan juga pejabat instansi-instansi terkait. Pengamatan dilakukan terhadap tingkat kesejahteraan pelaku perikanan dibandingkan dengan masyarakat lain yang bekerja diluar bidang perikanan. Data primer yang dikumpulkan antara lain: jenis armada dan alat tangkap yang digunakan, rata-rata trip, jumlah dan jenis hasil tangkapan nelayan per trip dalam kurun waktu tertentu, biaya-biaya dalam melakukan penangkapan, pendapatan dari 
hasil tangkapan, kebutuhan keluarga, serta informasi lainnya yang dirinci dalam kuisioner.

Data sekunder diperoleh dari Badan Pusat Statistik, Dinas Perikanan, Kantor Bupati, Kantor Camat, pelabuhan dan tempat pelelangan ikan, koperasi serta instansiinstansi terkait lainnya yang memiliki data sesuai dengan kebutuhan penelitian ini. Data sekunder antara lain berupa time series jenis dan jumlah hasil tangkapan, jumlah armada penangkapan, jumlah dan jenis alat tangkap, jumlah nelayan, tingkat harga, tingkat suku bunga, indeks harga konsumen, tingkat inflasi, peraturan yang mengatur pengelolaan sumberdaya perikanan di pesisir, dan data lainnya yang relevan terhadap tujuan penelitian.

Teknik pengambilan sampel yang digunakan adalah purposive sampling yaitu nelayan yang menggunakan alat tangkap untuk menangkap ikan kerapu.

\section{Metode Analisis Data}

Metode analisis data berdasarkan model pendekatan yang telah dikemukakan sebelumnya terdiri dari metode untuk pendugaan parameter-parameter yang digunakan dan metode untuk pendugaan nilai optimal pengelolaan sumberdaya ikan kerapu di perairan Kepulauan Seribu pada rezim pengelolaan maximum economic yield. Parameter yang digunakan dalam penelitian ini dapat dibedakan yaitu parameter biologi dan parameter ekonomi. Parameter biologi yang diduga adalah parameter pertumbuhan intrinsik ikan ( $r$ ), daya dukung lingkungan (K) dan kemampuan alat tangkap dalam melakukan penangkapan ikan (q). Sedangkan parameter ekonomi yaitu harga input dalam melakukan penangkapan dan harga output ikan kerapu.

Parameter biologi diduga dengan menggunakan model surplus produksi yang dikemukakan Clark, Yoshimoto and Pooley (1992) lebih dikenal dengan metode CYP. Persamaan CYP dalam bentuk matematis dapat ditulis sebagai berikut :

$\ln \left(U_{t+1}\right)=\frac{2 r}{(2+r)} \ln (q K)+\frac{(2-r)}{2+r} \ln \left(U_{t}\right)-\frac{q}{(2+r)}\left(E_{t}+E_{t+1}\right)$

dimana :

$U_{t}=\frac{C}{E}$

Dengan meregresikan hasil tangkap per unit input (effort) yang dilambangkan dengan $U$ pada periode $t+1$ dan dengan $U$ pada periode $t$, serta penjumlahan input pada periode $t$ dan $t+1$, akan diperoleh koefisien $r, q$ dan K secara terpisah. Selanjutnya setelah disederhanakan persamaan diatas dapat diestimasikan dengan OLS melalui :

$$
\operatorname{Ln}\left(U_{t+1}\right)=C_{1}+C_{2} \ln \left(U_{t}\right)+C_{3}\left(E_{t}+E_{t+1}\right)
$$

Sehingga nilai parameter $r$, $q$ dan $\mathrm{K}$ dapat diperoleh melalui persamaan berikut :

$$
\begin{aligned}
& r=\frac{2(1-\mathrm{C} 2)}{(1+\mathrm{C} 2)} \\
& \mathrm{q}=-\mathrm{C}_{3}(2+\mathrm{r}) \\
& K=\frac{e^{C_{1}(2+r) /(2 r)}}{q}
\end{aligned}
$$

Dalam menentukan jumlah input (upaya penangkapan) yang digunakan terlebih dahulu dilakukan standarisasi terhadap upaya penangkapan. Standarisasi dilakukan untuk memperoleh jumlah alat tangkap yang mempunyai hasil tangkapan per unit upaya penangkapan yang sama. Dalam penelitian ini, standarisasi alat tangkap yang dilakukan mengacu kepada metode yang dikemukakan oleh Tampubolon et al. (1983) dalam Tinungki (2005). Metode standarisasi alat tangkap tersebut adalah:

$$
\begin{aligned}
& C P U E_{s t}=\frac{C_{s t}}{E_{s t}} \\
& F P I_{s t}=\frac{C P U E_{s t}}{C P U E_{s t}}
\end{aligned}
$$




$$
\begin{gathered}
C P U E_{i}=\frac{C_{i}}{E_{i}} \\
F P I_{i}=\frac{C P U E_{i}}{C P U E_{s t}}
\end{gathered}
$$

dimana:

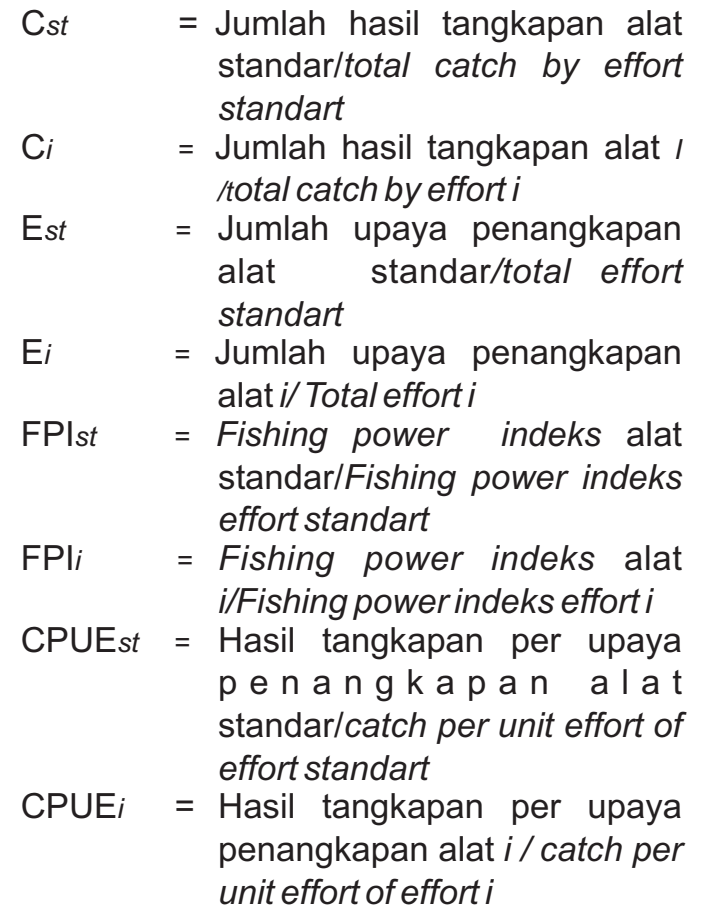

Parameter harga dan biaya dalam penelitian ini diasumsikan konstan. Pendugaan harga ikan kerapu hasil tangkapan diperoleh dari data sekunder. Harga ikan kerapu dibedakan berdasarkan ikan kerapu yang dijual dalam kondisi hidup dan segar. Ikan kerapu hasil tangkapan yang dijual dalam kondisi hidup lebih mahal dibandingkan dijual dalam kondisi segar. Komponen biaya yang digunakan terdiri dari biaya investasi, biaya variable dan biaya tetap.

Pendugaan nilai optimal pada pengelolaan sumberdaya ikan kerapu di perairan Kepulauan Seribu secara ekonomi terdiri dari pendugaan terhadap jumlah upaya penangkapan optimal, jumlah penangkapan optimal dan biomas optimal. Penentuan nilai optimal tersebut diperoleh berdasarkan pendekatan yang digunakan. Nilai optimal untuk masing-masing variable tersebut adalah:

$$
E^{*}=\frac{r}{2 q}\left(1-\frac{c}{p q K}\right)
$$

dimana :

$$
\begin{aligned}
& c=\text { biaya/cost of fishing } \\
& p=\text { harga/fish price }
\end{aligned}
$$

Dengan mensubstitusikan nilai optimal $E$ ke persamaan h, maka akan diperoleh jumlah hasil tangkapan yang optimal

$$
h^{*}=\frac{r K}{4}\left(1+\frac{c}{p q K}\right)\left(1-\frac{c}{p q K}\right)
$$

dan jumlah biomass adalah sebagai berikut:

$$
x^{*}=\frac{h}{q \cdot E}
$$

dimana :

$$
\begin{aligned}
h^{*}= & \text { Jumlah hasil tangkapa n } \\
& \text { optimal/totaloptimal harvest } \\
x^{*}= & \text { Jumlah biomassa optimal/total } \\
& \text { optimal biomass }
\end{aligned}
$$

\section{HASIL DAN PEMBAHASAN}

\section{Pendugaan Parameter}

Ikan kerapu merupakan jenis ikan yang selalu menarik perhatian nelayan di Kepulauan Seribu untuk melakukan penangkapan karena ikan tersebut mempunyai nilai ekonomis yang tinggi jika dijual dalam kondisi hidup. Ikan kerapu banyak ditangkap dengan menggunakan alat tangkap bubu dan pancing. Alat tangkap ini dipilih untuk menjaga supaya ikan hasil tangkapan tetap dalam kondisi hidup.

Dalam menduga parameter biologi dalam pemanfaatan sumberdaya ikan kerapu di perairan Kepulauan Seribu diperlukan adanya data jumlah produksi dan jumlah alat tangkap yang digunakan untuk menangkap ikan kerapu tersebut. Karena ada dua jenis alat 
tangkap yang dominan digunakan untuk penangkapan ikan kerapu maka alat tangkap tersebut perlu distandarisasi untuk keseragaman ukuran. Standarisasi alat tangkap dilakukan dengan mengetahui fishing power index (indeks kemampuan tangkap) dari alat tangkap tersebut. Fishing power index = FPI masing-masing alat tangkap diperoleh dari formula yang dikemukakan Tampubolon et al. (1983) dalam Tinungki (2005).

Fishing power index diperoleh dari nilai CPUE (catch per unit effort) suatu alat tangkap dibagi dengan nilai CPUE alat tangkap standar. Fishing power index untuk alat tangkap standar adalah 1. Alat standar dalam penelitian ini adalah bubu (trapnet) karena hasil tangkapan bubu terhadap ikan kerapu lebih besar dibandingkan alat tangkap pancing. Dari data Dinas Peternakan, Perikanan dan Kelautan Provinsi DKI Jakarta tahun 2004, jumlah alat tangkap bubu adalah 164 unit dengan jumlah produksi 63,38 ton.
Rata-rata hasil tangkapan per unit alat tangkap bubu setiap tahunnya adalah $193,5 \mathrm{~kg}$ sedangkan rata-rata hasil tangkapan per unit alat tangkap pancing adalah 15,26 kg per tahun (Dinas Peternakan, Perikanan dan Kelautan, 1995-2005). Fishing power index alat tangkap pancing setiap tahunnya dan jumlah alat tangkap yang dioperasikan untuk menangkap ikan kerapu di perairan Kepulauan Seribu disajikan pada (Tabel 1).

Jumlah alat tangkap standar setara dengan bubu diperoleh dari jumlah alat tangkap pancing dikali dengan FPI pancing ditambah dengan jumlah alat tangkap bubu. Alat tangkap standar lebih rendah dibandingkan dengan jumlah alat tangkap bubu dan pancing. Alat tangkap standar ini selanjutnya digunakan untuk menduga nilai parameter biologi $r$, $q$ dan $K$.

Pendugaan parameter biologi ikan kerapu di perairan Kepulauan Seribu dilakukan dengan menggunakan metode yang dikemukakan oleh Clark, Yoshimoto and

Tabel 1. Jumlah Alat Tangkap Standar Dan Fishing Power Index Pancing di Kepulauan Seribu, 1994-2004

Table 1. Number of Standardizes Fishing Effort And Fishing Power Index Of Hookline in the Kepulauan Seribu, 1994-2004

\begin{tabular}{ccccc}
\hline $\begin{array}{c}\text { Tahun/ } \\
\text { Year }\end{array}$ & $\begin{array}{c}\text { Bubu I } \\
\text { Trapnet }\end{array}$ & $\begin{array}{c}\text { CPUE } \\
\text { Pookline }\end{array}$ & $\begin{array}{c}\text { FPI Pancing/ } \\
\text { FPI Hookline }\end{array}$ & $\begin{array}{c}\text { Jumlah alat } \\
\text { tangkap standar } \\
\text { ITotal effort } \\
\text { standart }\end{array}$ \\
\hline 1994 & 134,4792 & 29,2556 & 0,2175 & 193 \\
1995 & 52,4217 & 7,9759 & 0,1521 & 341 \\
1996 & 96,5358 & 9,2060 & 0,0954 & 207 \\
1997 & 97,1254 & 9,4741 & 0,0975 & 227 \\
1998 & 109,5890 & 11,4185 & 0,1042 & 247 \\
1999 & 217,3217 & 18,0566 & 0,0831 & 267 \\
2000 & 204,0064 & 19,3691 & 0,0949 & 288 \\
2001 & 110,2306 & 11,1979 & 0,1016 & 308 \\
2002 & 446,4257 & 28,9873 & 0,0649 & 248 \\
2003 & 272,8050 & 11,0079 & 0,0404 & 213 \\
2004 & 387,5619 & 11,9353 & 0,0308 & 217 \\
\hline
\end{tabular}

Sumber/ Sources : Analisis Data, 2006/ Data Analiysis, 2006 
Pooley, 1992 (CYP) diacu dalam Fauzi, 2004. Metode tersebut menggunakan OLS (Ordinary Least Square) atau regresi linier dengan menggunakan data logaritma CPUE pada waktu $t+1$ sebagai peubah tidak bebas dan logaritma CPUE pada waku t dan jumlah effort pada waktu $t$ dan $t+1$ sebagai peubah bebas (Tabel 2).

$$
\ln \left(U_{t+1}\right)=3,3272+0,475 \ln \left(U_{t}\right)-0,001098\left(E_{t}+E_{t+1}\right)
$$

Dari nilai tersebut dapat diduga nilai tingkat pertumbuhan intrinsik ( $r$ ), koefisien kemampuan tangkap (q) dan daya dukung lingkungan perairan (K). Koefisien tersebut disajikan pada Tabel 3 .

Fungsi pertumbuhan perikanan kerapu di

Tabel2. Data Input Untuk Analisis Surplus Produksi Menggunakan Model CYP di Kepulauan Seribu, 1994-2004

Table 2. Input Data For Production Surplus Analysis Using CYP Model in Kepulauan Seribu, 1994-2004

\begin{tabular}{cccc}
\hline $\begin{array}{c}\text { Tahun/ } \\
\text { Year }\end{array}$ & $\begin{array}{c}\text { LN CPUE } \\
\text { pada tahun+1 (t+1)/ } \\
\text { LN CPUE at year +1 } \\
(\mathbf{t + 1})\end{array}$ & $\begin{array}{c}\text { LN CPUE } \\
\text { pada tahun } \mathbf{~ ( t ) / ~ L N ~} \\
\text { CPUE at year } \mathbf{t}(\mathbf{t})\end{array}$ & $\begin{array}{c}\text { Et + Et+1 pada tahun t } \\
\text { dan } \mathbf{t + 1 /} \text { Et }+ \text { Et+1 at } \\
\text { year } \mathbf{t} \text { and } \mathbf{t + 1}\end{array}$ \\
\hline 1994 & 4,0319 & 4,9740 & 534,0857 \\
1995 & 4,6425 & 4,0319 & 548,5113 \\
1996 & 4,6486 & 4,6425 & 434,2555 \\
1997 & 4,7693 & 4,6486 & 474,4926 \\
1998 & 5,4539 & 4,7693 & 514,7298 \\
1999 & 5,3907 & 5,4539 & 554,9669 \\
2000 & 4,7751 & 5,3907 & 595,2040 \\
2001 & 6,1738 & 4,7751 & 555,7720 \\
2002 & 5,6813 & 6,1738 & 460,8681 \\
2003 & 6,0324 & 5,6813 & 430,0187 \\
2004 & & & \\
\hline
\end{tabular}

Sumber/Sources : Analisis Data, 2006/ Data Analiysis, 2006

Output OLS memberikan nilai intersept $(a=3,3272)$, koefisien untuk variabel

$\ln \left(L b_{t} \rightarrow 0,4735\right)$ dan koefisien untuk variabel $\left(E_{t}+E_{t+1}\right)(\mathrm{c}=-0,001098)$ atau
Perairan Kepulauan Seribu dengan menggunakan fungsi pertumbuhan logistik dapat ditulis sebagai berikut:

$F(x)=0,715 x\left(1-\frac{x}{186267,28}\right)$

Tabel 3. Parameter Biologi Sumberdaya Ikan Kerapu di Kepulauan Seribu, 2006

Table 3. Biological Parameters of Groupers in the Kepulauan Seribu, 2006

\begin{tabular}{|c|c|c|c|}
\hline No & $\begin{array}{c}\text { Koefisien/ } \\
\text { Coefisien }\end{array}$ & Definisi /Definition & $\begin{array}{l}\text { Nilai/ } \\
\text { Value }\end{array}$ \\
\hline 1. & r & tingkat pertumbuhan intrinsic /intrinsic growth rate & 0,715 \\
\hline 2. & q & Kemampuan tangkap/ catchability coefisient & 0,00298 \\
\hline 3. & $\mathrm{~K}$ & daya dukung perairan /carrying capacity & $186.267,28$ \\
\hline
\end{tabular}


Pendugaan harga ikan kerapu yang ditangkap di perairan Kepulauan Seribu diperoleh dari data primer dan data sekunder. Data primer diperoleh dari hasil wawancara dengan nelayan, sedangkan data sekunder diperoleh dari Dinas Peternakan, Perikanan dan Kelautan Provinsi DKI Jakarta. Alat tangkap yang umum digunakan untuk menangkap ikan kerapu adalah bubu dan pancing. Ikan kerapu hasil tangkapan dengan menggunakan alat tangkap bubu pada umumnya dijual dalam kondisi hidup sedangkan dengan menggunakan alat tangkap pancing lebih banyak dijual dalam kondisi segar.

Hasil wawancara dengan nelayan diperoleh rata-rata harga ikan kerapu adalah Rp. 60.000 per kg untuk ikan yang dijual dalam kondisi hidup dan Rp. 12.000 per kg untuk ikan yang dijual dalam kondisi segar. Sedangkan rata-rata harga untuk ikan kerapu hasil budidaya adalah Rp. 105.000 per kg. Harga ikan kerapu yang dijual dalam kondisi segar atau mati diperoleh dari data sekunder semenjak tahun 1994 sampai dengan tahun 2003. Harga yang diperoleh tersebut adalah rata-rata harga nominal setiap tahun. Supaya data tersebut dapat diperbandingkan setiap tahunnya maka yang digunakan adalah harga riil. Harga riil diperoleh dari harga nominal dibagi dengan indeks harga konsumen dengan tahun dasar pada tahun 2002. Harga nominal, indeks harga konsumen dan harga riil disajikan pada (Tabel 4).

Penentuan harga untuk analisis selanjutnya dengan menggunakan proporsi produksi ikan kerapu dengan menggunakan alat tangkap bubu dan pancing, dan juga dengan asumsi bahwa semua ikan yang ditangkap dengan menggunakan alat tangkap

Tabel 4. Harga Nominal, Indeks Harga Konsumen Dan Harga Riil Ikan Kerapu di Propinsi DKI Jakarta, 1994-2004

Table 4. Nominal Prices, Consumer Price Indexs And Real Prices Of Groupers in DKI Jakarta Province, 1994-2004

\begin{tabular}{cccc}
\hline & \multicolumn{3}{c}{ Hasil Tangkapan/ Harvest } \\
\cline { 2 - 4 } Tahun/Year & $\begin{array}{c}\text { Harga Nominal/ } \\
\text { Nominal Price }\end{array}$ & IHK 2002=100 & Harga Riil/Real Price \\
\hline 1994 & $1.893,00$ & 31,25 & $6.058,05$ \\
1995 & $2.176,00$ & 34,23 & $6.357,04$ \\
1996 & $2.243,00$ & 36,71 & $6.109,25$ \\
1997 & $1.000,00$ & 64,04 & $1.561,46$ \\
1998 & $7.360,99$ & 65,17 & $11.294,56$ \\
1999 & $9.796,53$ & 77,29 & $12.674,58$ \\
2000 & $14.277,89$ & 80,16 & $17.810,98$ \\
2001 & $23.723,12$ & 89,38 & $26.540,71$ \\
2002 & $14.975,80$ & 100,00 & $14.975,80$ \\
2003 & $16.704,75$ & 106,59 & $15.672,60$ \\
2004 & & & \\
Rata-rata & & & $11.905,50$ \\
Harga/Average & $9.415,11$ & & \\
Price & & & \\
\hline
\end{tabular}

Sumber/Sources : Analisis Data, 2006/ Data Analiysis, 2006 
bubu dijual dalam kondisi hidup dan ikan yang ditangkap dengan menggunakan alat tangkap pancing dijual dalam kondisi segar. Rata-rata produksi ikan kerapu di perairan Kepulauan Seribu menggunakan alat tangkap bubu tiga kali lebih banyak dibandingkan produksi ikan kerapu dengan menggunakan alat tangkap pancing,

Rata-rata harga ikan kerapu hidup dan kerapu mati diperoleh dengan menjumlahkan nilai produksi dengan menggunakan alat tangkap bubu dan pancing, kemudian dibagi dengan total produksi dari kedua alat tangkap tersebut. Nilai produksi ikan kerapu hasil tangkapan dengan menggunakan alat tangkap bubu diperoleh dari jumlah produksi bubu dikalikan dengan harga sebesar Rp. 60.000. Nilai produksi ikan kerapu hasil tangkapan dengan menggunakan alat tangkap pancing diperoleh dari perkalian harga riil setiap tahun dengan jumlah produksi pancing. Dengan demikian diperoleh rata-rata harga ikan kerapu di Perairan Kepulauan Seribu adalah Rp. 48.190 per kg.

Komponen biaya yang dihitung dibedakan menjadi tiga yaitu biaya investasi, biaya variabel dan biaya tetap. Biaya investasi terdiri dari biaya untuk pembelian kapal, mesin dan alat tangkap.

Biaya tersebut diperoleh dari harga kapal rata-rata dari seluruh jumlah responden bubu. Biaya alat tangkap adalah rata-rata jumlah bubu yang dibeli oleh nelayan dalam 1 tahun. Pembelian bubu dilakukan beberapa kali dalam 1 tahun karena umur teknis bubu hanya 3 sampai 7 bulan. Jumlah bubu yang dimiliki oleh nelayan juga bervariasi yaitu berselang antara 5 sampai 20 unit.

Biaya variabel terdiri dari biaya untuk BBM bagi kapal yang bermesin, biaya perbekalan, perbaikan kapal dan mesin serta untuk pembelian alat tangkap. Biaya BBM diperoleh dari rata-rata biaya yang dikeluarkan nelayan dalam 1 tahun, begitu juga untuk biaya perbekalan dan perbaikan kapal dan mesin. Biaya tetap yang ditanggung nelayan adalah biaya penyusutan dari kapal dan mesin sesuai dengan umur teknis. Total biaya yang dikeluarkan nelayan dengan menggunakan alat tangkap bubu adalah Rp. 7.064.417

Total biaya investasi untuk pembelian kapal dan mesin menggunakan alat tangkap pancing lebih besar dibandingkan alat tangkap bubu. Rata-rata pembelian kapal dan mesin dari seluruh jumlah responden dengan mengunakan alat tangkap pancing adalah Rp.12.160.000 dan alat tangkap pancing Rp. 30.000. Biaya variabel terdiri dari biaya BBM, pebekalan, perbaikan kapal dan mesin dan total pembelian pancing dalam satu tahun. Rata-rata biaya variabel adalah $\mathrm{Rp}$. 7.378.970. Biaya tetap terdiri dari biaya untuk penyusutan kapal dan mesin sebesar Rp. 2.624.166. Total biaya adalah Rp. Rp. 10.003.316.

\section{Pendugaan Nilai Optimal}

Tingkat eksploitasi ikan kerapu yang optimal diperoleh dengan bantuan program microsoft excel seperti yang dikemukakan Fauzi (2004). Nilai tersebut dapat ditentukan setelah diketahui parameter biologi dan juga parameter ekonomi yang telah dikemukakan sebelumnya. Dengan menggunakan persamaan no 3 diatas maka dapat diketahui tingkat biomas optimal ikan kerapu di perairan Kepulauan Seribu adalah122.694,07 kg per tahun. Dari jumlah biomas tersebut, jumlah ikan kerapu yang boleh dimanfaatkan atau ditangkap adalah 29.940,97 kg per tahun. Jumlah alat tangkap optimal yang noleh dioperasikan untuk menangkap ikan kerapu adalah 82 unit per tahun setara dengan alat tangkap bubu.

Berdasarkan data jumlah produksi ikan kerapu di perairan Kepulauan Seribu pada tahun 2004 yang dikemukakan Dinas Peternakan, Perikanan dan Kelautan Propinsi DKI Jakarta yaitu sebesar 63,38 ton, menunjukkan bahwa tingkat pemanfaatan yang dilakukan telah melebihi jumlah ikan kerapu yang boleh dimanfaatkan secara optimal. Dilihat dari jumlah alat tangkap yang beroperasi di perairan Kepualau Seribu juga 
telah menunjukkan adanya kelebihan armada yang dioperasikan sebanyak 82 unit dari tingkat optimal jumlah alat tangkap yang diperbolehkan.

Dengan mengoperasikan jumlah upaya penangkapan pada tingkat optimal yaitu 82 unit dengan hasil tangkapan sebesar 29,9 ton akan diperoleh nilai manfaat ekonomi atau rente ekonomi sebesar Rp. 747,60 juta per tahun. Untuk lebih jelasnya jumlah biomas optimal, jumlah pemanfaatan optimal dan aktual serta jumlah alat tangkap optimal dan actual disajikan pada Tabel 5 .

\section{KESIMPULAN DAN IMPLIKASI KEBIJAKAN}

Penangkapan ikan kerapu di perairan Kepulauan Seribu telah melebihi tingkat pemanfaatan yang optimal pada rejim pengelolaan Maximum Economic Yield (MEY). Banyaknya jumlah upaya penangkapan yang diusahakan oleh nelayan di Perairan Kepulauan Seribu adalah 164 unit dengan hasil tangkapan 63,38 ton, sedangkan jumlah upaya penangkapan optimal secara ekonomi adalah 82 unit dengan hasil tangkapan 29,94 ton per tahun. Dengan demikian diperlukan kebijakan pemerintah untuk membatasi tingkat pemanfaatan sumberdaya ikan kerapu tersebut, sehingga tingkat pemanfaatan dapat dilakukan pada kondisi optimal dan rente ekonomi maksimum dapat dicapai.

\section{DAFTAR PUSTAKA}

Clark, C. 1985. Bioeconomic Modelling and Fisheries Management. John Wiley and Sons. New York.

Dinas Peternakan, Perikanan dan Kelautan Provinsi DKI Jakarta. 2005. Buku Statistik Tahunan Perikanan. Dinas Peternakan, Perikanan dan Kelautan. Jakarta

Fauzi, A. 2004. Ekonomi Sumber Daya Alam dan Lingkungan. PT. Gramedia Pustaka Utama. Jakarta.

Schaefer, M.B. 1954. Some Aspect of the Dynamics of Populations Important to the Management of Commercial Marine Fishery Bull. Interm-Am. 1957. A Study of the Dynamics of the Fishery for Yellowfin Tuna in the Eastern Tropical Pacific Ocean. Bull. Interm-Am.

Tinungki, G.M. 2005. Evaluasi Model Produksi Surplus dalam Menduga Hasil Tangkapan Maksimum Lestari untuk Menunjang Kebijakan Pengelolaan Perikanan Lemuru di Selat Bali. Disertasi Institut Pertanian Bogor. Bogor.

Tabel 5. Biomassa Optimal, Jumlah Penangkapan Dan Effort Optimal Dan Aktual Serta Maksimum Rente Ekonomi Ikan Kerapu di Kepulauan Seribu

Table 5 Optimum Biomass, Harvest and Effort Optimum and Actual, Economic Rent Maximum of Groupers in the Kepulauan Seribu

\begin{tabular}{clcrr}
\hline Simbol & \multicolumn{1}{c}{ Definisi/Definition } & $\begin{array}{c}\text { Satuan/ } \\
\text { Unit }\end{array}$ & $\begin{array}{c}\text { Optimal/ } \\
\text { Optimum }\end{array}$ & $\begin{array}{r}\text { Aktual/ } \\
\text { Actual }\end{array}$ \\
\hline X & Stok ikan/biomass & $\mathrm{kg}$ & $122.694,07$ & \\
$\mathrm{~h}$ & Hasil tangkapan/harvest & $\mathrm{kg}$ & $29.940,97$ & $63.380,00$ \\
$\mathrm{E}$ & Upaya penangkapan/effort & unit & 82 & 164 \\
Phi & Rente/profiit & Rp. & 747.603 .749 & \\
& & &, 82 &
\end{tabular}

Sumber/Sources : Analisis Data, 2006/ Data Analiysis, 2006 